\title{
Lash, Hall, Maffesoli: as forças ativas do desejo e a comunicação
}

\author{
Lash, Hall, Maffesoli: the active forces of desire and communication \\ Lash, Hall, Maffesoli: las fuerzas activas del deseo y la comunicación \\ Eduardo Portanova Barros ${ }^{1}$ \\ Antônio César Santos Fonseca ${ }^{2}$
}

\begin{abstract}
Resumo
Este artigo analisa a crítica de Scott Lash ao esquecimento, segundo ele, de abordagens genealógicas em relação a dois autores: Deleuze e Nietzsche. Para Lash, são teóricos marginalizados e que ele, Lash, procura inserir nesse debate. Para complementar essa abordagem, nós acreditamos na pertinência de uma abordagem fenomenológica (o que se dá a ver) de um imaginário cotidiano, e na reflexão de Hall em torno do sujeito sociológico. Acrescentamos nós: comunicativo. Concluímos, mas deixando o caminho em aberto, que Lash, Hall e Maffesoli têm em comum a visão de que estamos em plena sociedade pós-moderna e complexa como palavra-problema e não como palavra-solução, para o melhor ou o pior.
\end{abstract}

Palavras-chave: Sociologia. Pós-modernidade. Lash. Hall. Maffesoli.

\begin{abstract}
This article analyzes the criticism of Scott Lash to the forgetfulness, according to him, of genealogical approaches to two authors: Deleuze and Nietzsche. For Lash, they are marginalized theorists and he, Lash, seeks to insert them in that debate. To complement this approach, we believe in the pertinence of a phenomenological sociology of Maffesolian character and in Hall's reflection around the sociological subject from communication. We conclude, but leaving the way open, that Lash, Hall and Maffesoli have in common the view that we are in the full postmodern society (a problematic word as Morin said) to the best or the worst.
\end{abstract}

Keywords: Sociology. Postmodernity. Lash. Maffesoli. Hall.

\section{Resumen}

Este artículo analiza la crítica de Scott Lash al olvido, según él, de enfoques genealógicos en relación a dos autores: Deleuze y Nietzsche. Para Lash, son teóricos marginados y que él, Lash, busca insertar en ese debate. Para complementar este enfoque, creemos en la pertinencia de una lectura fenomenológica (lo que se da a ver) de cuño maffesoliano, sin barreras, y en la reflexión de Hall en torno al sujeto sociológico em comunicación. Concluimos, pero dejando el camino abierto, que Lash, Hall y Maffesoli tienen en común la visión de que estamos en plena sociedad posmoderna y compleja (en términos de Morin, o sea, como palabra-problema y no como palabra-solución) para el mejor o el peor.

Palabras clave: Sociología. Posmodernidad. Lash. Maffesoli. Hall.

\footnotetext{
${ }^{1}$ Doutor em Comunicação Social pela PUCRS. Professor visitante do PPGCOM-UFG, Goiânia-GO. e-mail: eduardoportanova@hotmail.com.

${ }^{2}$ Mestre pelo PPG em Ciências Sociais da Unisinos, Porto Alegre (RS). e-mail: fonsecahistoria@yahoo.com.br.
}

Comun. \& Inf., Goiânia, GO, v. 21, n. 2, p. 32-50, jun./set. 2018. 


\section{INTRODUÇÃO}

britânico Scott Lash, em "Sociologia do pós-modernismo" (1997), no
capítulo "A genealogia e o corpo: Foucault, Deleuze e Nietzsche", coloca
em discussão dois autores que, segundo ele, têm sido marginalizados ao se falar de desejo: Deleuze e Nietzsche. Para Lash, "Deleuze pode reclamar o mesmo estatuto de genealogista que Foucault” (1997, p. 82). Quanto a Nietzsche, o teórico do nascimento da tragédia (tragédia que, para ele, Nietzsche, é o antagonismo entre Apolo sonhador e Dionísio “embriagado"), Lash afirma que se presta pouca atenção às questões referentes ao método genealógico na obra dele. A proposta de Lash (1997), portanto, é ampliar, como ele diz, a discussão. E ampliar, na concepção dele, é falar de genealogia seguindo não apenas Foucault, que, portanto, não seria o único genealogista, mas também em conformidade com Deleuze e Nietzsche. Esse é um primeiro ponto. E esse é um ponto singular no texto de Lash, ou seja, o de uma falta que o motiva.

Lash procura resgatar teorias de outros autores para entender essa amplitude que ele mesmo se propôs a fazer. Vai de Descartes a Guattari, passando por Marx, Lacan, Derrida, Barthes, Merleau-Ponty, Lyotard, Habermas, Bataille, Luhmann, Weber, Rorty, Sartre e Bourdieu, entre outros. Procura, a exemplo de muitos simpatizantes dessa tese, transformar a pós-modernidade em teoria social, se já não o é. Não quer dizer, com isso, que ele a reivindique, e sim que, através do texto e da forma como ele, Lash, se expressa, a pósmodernidade passa a adquirir uma importância e uma respeitabilidade que muitos de seus opositores não reconhecem nela por meio do desejo. O que chama atenção no texto de Lash, primeiramente, é a comparação entre Foucault e Deleuze. De acordo com Lash (1997), Deleuze pensa no corpo como superfície de interseção entre, de um lado, forças libidinais e, de outro, forças sociais exteriores, por meio de um jogo recíproco entre elas. O mesmo jogo recíproco que Nietzsche aponta no início da tragédia: "Ambos os impulsos caminham lado a lado" (2007, p. 24).

Foucault, por outro lado, pensa, ainda conforme Lash (1997), em termos de discurso e ignora, segundo ele, as forças ativas do desejo. No momento em que faz essa comparação, a de que Deleuze leva em conta tanto as forças ativas (que substituem o corpo passivo) do desejo quanto as reativas (ou seja, normalizadoras) e que Foucault não, pois só considera as últimas (reativas), Lash nada mais faz do que evidenciar a dívida de Foucault com o estruturalismo. Este traço estruturalista é bastante claro, por exemplo, no texto do seu ingresso 
no Collège de France, em 1969, intitulado "O que é um autor?” (1992). Foucault apresenta uma nova visão da autoria, não mais ligada ao gênio pessoal e individualista do criador, não há dúvida. "Na escrita, não se trata da manifestação ou da exaltação do gesto de escrever, nem da fixação de um sujeito na linguagem. [...] o sujeito da escrita está desaparecendo" (FOUCAULT, 1992, p. 35).

Também não há dúvida de que, ao ver as coisas sob esse prisma, Foucault amplia, a exemplo do que Lash diz fazer em relação à genealogia, a discussão para o deslocamento do autor para outra esfera de percepção, que não é a dele mesmo. Assim, Foucault abre caminho para novas teorias sobre a questão autoral, reforçando, assim, a tese de Barthes (nos anos 1970) sobre a morte do autor e o prazer do texto. A ênfase no título desse livro de Barthes ("O prazer do texto") é clara: o que importa é, obviamente, o texto. "Como instituição, o autor está morto: sua pessoa civil, passional, biográfica, desapareceu; desapossada, já não exerce sobre sua obra a formidável paternidade que a história literária, o ensino, a opinião tinha o encargo de estabelecer" (BARTHES, 1987, p. 37). Caso contrário, poderia ser: "O prazer da autoria". Por sua vez, a contribuição de Deleuze/Guattari na constituição do desejo, segundo Lash, é a de substituir o corpo passivo por forças ativas do desejo, sem antes situar o discurso sobre o corpo nos períodos clássico (XVII e XVIII) e moderno (XIX).

\section{NIETZSCHE E A VONTADE DE PODER}

Durante o período absolutista, prevalecia a crueldade física. No "moderno", prevalecia o discurso. Foucault irá falar dos processos genealógicos como descendência e emergência. No primeiro, prevalecem o sangue, a tradição e a classe. É o corpo marcado pela história, o que não acontece no segundo, pontuado mais por um sentido de emergência. Vemos, aqui, que Lash coloca lado a lado Foucault e Deleuze, tentando reequilibrar a discussão na qual, segundo o autor, Deleuze estava em desvantagem, assim como Nietzsche. O que Lash destaca de Nietzsche é a questão do corpo como multiplicidade de forças através da "vontade de poder". Nesse aspecto, o espiritual e o corporal passariam a coexistir dentro do corpo em estado de constante tensão, e mais do que isso: uma tensão irreconciliável, como é própria da natureza de todo tensionamento enquanto tensionamento.

Nada mais trágico. Nada mais pós-moderno. Nietzsche é o filósofo da pósmodernidade a partir do momento em que anuncia a morte de Deus. Se na modernidade o 


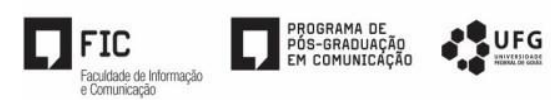

projeto era seguro e o progresso certo, depois dessa hipótese, também se esvazia o sentido das coisas. A esperança, a partir de Nietzsche, é uma espécie de quimera. Nem por isso, vivemos com menos ardor e paixão. Nietzsche insiste no trágico, o que ele deixa muito claro em "O nascimento da tragédia" (2007). Toda a obra dele nos remete ao pensamento - que é trágico das polaridades. Apolo e Dionísio "incitam-se mutuamente”, escreve Nietzsche (2007, p. 24). "Na maioria das vezes em discórdia" (NIETZSCHE, 2007, p. 24). Temos de abrir uns parênteses aqui. A discussão sobre o desejo em Lash nos remete à era pós-moderna. Se assim o é, temos de justificar o que significa, na nossa acepção, o termo pós-moderno, a fim de não cairmos numa espécie de obscurantismo.

Existem várias ideias a respeito, isso porque o termo "pós" é carregado de interrogações. Gianni Vattimo, em “A sociedade transparente” (1992), diz que existe um ideal de transparência na mídia, por exemplo, mas que não é nítido. Vattimo (1992) lembra que a mídia não só não é transparente como também, por outro lado, dissolve a centralidade dos pontos de vista. Para Vattimo (1992), a mídia, portanto, é uma questão pós-moderna. “A tese que pretendo propor é que na sociedade dos media, em vez de um ideal de emancipação modelado pela autoconsciência completamente definida, tem antes a oscilação" (VATTIMO, 1992, p. 13). Esse é um ponto. Outro que ele destaca é o seguinte. Para Vattimo (2002), dois filósofos podem ser considerados os "pais fundadores da pós-modernidade". Eles são Nietzsche - daí a relação com a ideia de Lash - e Heidegger. Em "O fim da modernidade" (2002), Vattimo relaciona aquilo que considera tanto a conclusão de Nietzsche quanto a de Heidegger sobre o fim da chamada época moderna, respectivamente as teses do "eterno retorno" (tese na qual não se tem mais por horizonte a sucessão de fato históricos) e a do "ultrapassamento da metafísica" (na qual o Ser não se explica para o "além" da matéria, e sim no aqui-e-agora, que Heidegger chamará de o Ser-aí).

A arte trágica de Nietzsche é conhecida pelo termo dionisíaco, isso porque remete ao Deus Dionísio, o Deus do Vinho e, portanto, da embriaguez. O “eu”, em outras palavras, fragmenta-se, como vimos anteriormente. Ou desintegra-se. Portanto, Nietzsche irá apresentar dois instintos básicos no ser humano, o "estético" e o "racionalista". Estes dois instintos estéticos se diferenciam, sim, mas se opõem, também. Conforme Nietzsche (2002, p. 82), trata-se de uma esfera artística apolínea e a negação disso, o seu contrário. Vattimo, dessa forma, acredita que, baseando-se em Nietzsche, "a essência do moderno só se torna verdadeiramente visível a partir do momento em que o mecanismo da modernidade se 
distancia de nós" (2002, p. 102). Lévi-Strauss, por sua vez, nos recorda que na história dos povos havia uma história quente e outra fria, e lembrava que o que as distinguia era o ritmo da mudança social. Observaremos que, de tempos em tempos, ocorre uma transformação da ordem anteriormente estabelecida para outra que se coloca como propositora de novos paradigmas, substituindo o anterior, como se houvesse um rompimento.

\section{LASH, PÓS-MODERNISMO E DESEJO}

Esse interregno entre um período anterior e outro posterior, ocorrendo uma mudança na forma de pensar e agir (e sobre a própria condição humana) tem impacto que se reverbera por toda a sociedade. Quando Lash, portanto, fala da pós-modernidade e do desejo, a intenção dele é analisar o conceito de pós-modernidade cultural na teoria francesa, criticada, por sua vez, por Habermas por se dar primazia ao estético. Lash, porém, discorda. Ele diz que a estética, no sentido dos franceses, "é prática política" e não "estética transcendental". De fato, quando os teóricos franceses da Nouvelle Vague, para falar da área cinematográfica, se envolveram em discussões com os defensores da "ancienne vague" (ou seja, "velha onda", e não "nova", como na tradução literal da expressão), a prática política, no sentido de Lash, era clara. Era uma arte-ação. Lash mostra que, na pós-modernidade, com Foucault, Deleuze e Lyotard, aconteceu a ruptura com o formalismo e com o significante, a primazia do inconsciente, do desejo e dos impulsos libidinais e o divórcio com os vários estruturalismos, em especial os de Barthes, Lacan, Derrida e Habermas.

Portanto, não é difícil entender porque a relação do desejo com conceitos como cultura, civilização, identidade e outros é plenamente aceitável, visto que esses conceitos estão sempre num processo de metamorfose. Os sujeitos que estão nesse contexto também estão inseridos no processo de transformação. É temeroso trabalhar os conceitos de cultura e civilização com se fossem conceitos fixos dentro de uma ótica etnocêntrica. É bem provável que não obtivéssemos sucesso, visto que as transformações pelas quais o sujeito vem passando, tornando-o fragmentado e, por consequência, distante da visão de mundo, de Lash e o caráter da mudança naquilo que o autor chama de modernidade tardia. Primeiramente, apresenta "o sujeito do Iluminismo" em que o descreve como um indivíduo centrado, unificado, dotado das capacidades de razão. Destaca que o centro essencial desse indivíduo era a identidade. Portanto, uma concepção "individualista" do sujeito e de sua identidade. Em 
segundo lugar, nos mostra o "sujeito sociológico", que passa a refletir toda a complexidade do mundo moderno e a consciência de que este núcleo interior do sujeito não era autônomo nem autossuficiente, mas que era, sim, formado na relação com outras pessoas que se relacionam com ele, realizando uma espécie de troca de valores, sentidos, símbolos, cultura e, para ficarmos com nosso tema, o desejo (Lash). Na sociologia, os interacionistas simbólicos ou sociais é que elaboraram a concepção da identidade e do eu. Conforme essa visão, a identidade é formada na "interação entre o eu e a sociedade".

\subsection{O “SUJEITO SOCIOLÓGICO” DE LASH}

Nessa concepção, Hall (2014) continua afirmando que o sujeito até tem um núcleo ou essência interior que é o "eu real", mas este é modificado num diálogo contínuo com os mundos culturais "exteriores" e as identidades que esses mundos colocam à disposição. Neste contexto de novas abordagens que se apresentam no intuito de estudar e ver da aplicabilidade ou não do conceito de identidade, devemos lembrar que o paradigma europeu (marxista) e o paradigma norte-americano (foucaultiano, apesar de derivar de um europeu, Michel Foucault), analisando os novos movimentos sociais, se colocavam de forma antagônica, com posicionamentos diferentes. A Escola de Chicago propiciou abundante produção utilizada para estudos no campo das relações sociais, dando origem à chamada tradição do interacionismo. Esta produção emergiu num contexto histórico marcado por grandes transformações sociais, impulsionado pela ideia de progresso (GOHN, 1997, p. 27). Gohn destaca que a Escola de Chicago tinha uma orientação reformista: promover a reforma social de uma sociedade convulsionada em direção ao que se entendia como seu verdadeiro caminho, harmonioso e estável (1997, p. 27).

O Interacionismo Simbólico, que poderá nos servir também de alavanca teórica para a questão do desejo, além da fragmentação do indivíduo em Hall (2014), irá ressurgir depois de um longo período de intensa produção da Escola de Chicago, em virtude dos estudos de Goffman. Para Hall (2014), ainda, a identidade plenamente unificada, completa, segura e coerente é uma fantasia e, ao invés disso, à medida que os sistemas de significação e representação cultural se multiplicam, somos confrontados por uma multiplicidade desconcertante e cambiante de identidades possíveis, com as quais poderíamos nos identificar - ao menos temporariamente. Hall (2014), portanto, engajou-se na discussão que trata sobre hegemonia, dando especial atenção para questões que dizem respeito à globalização, que 
impulsionou a velocidade das informações e deu fluidez aos significados e aos símbolos por meio da mídia.

O autor nos mostra que é preciso compreender as demandas por reconhecimento partindo dos diversos processos que constituem as representações e identidades. Estas identidades, para Lash, estão ligadas à questão do desejo, conforme vimos antes. Ao se debruçar sobre a experiência dos caribenhos, Hall não identifica uma tradição única e verdadeira, muito menos a tentativa de reconstrução de um passado distante. $\mathrm{O}$ autor entende identidade como uma das diversas formas que temos de nos posicionarmos em relação às narrativas do passado e, também assim, posicionados por elas. As identidades são pensadas como desejos e construções que impõem de uma coerência imaginária a uma experiência de dispersão e fragmentação. Elas são oriundas de um lugar, tem uma determinante histórica, embora essas histórias estejam sempre em constante transformação (Hall).

A inexistência de fronteiras e o livre trânsito entre países e cidades possibilitam que as pessoas possam se movimentar livremente de um lugar para outro. $\mathrm{O}$ encontro entre pessoas com culturas e modos de vida e sistemas tão diversos possibilita o surgimento de um terceiro elemento, que é a identidade. Não uma identidade única com traços de uma homogeneidade, mas uma identidade surgida a partir de conceitos pós-modernos e do fenômeno da globalização. O deslocamento das identidades tem em uma das causas a globalização, que é definida como um complexo de processos e forças de mudança. A identidade nesse contexto aparece como híbrida, fruto de uma formação de várias conjunções que formam um ente único. Stuart Hall destaca que é importante estudar o impacto da globalização sobre a identidade, e ressalta que o tempo e o espaço são também as coordenadas fundamentais para esse sistema de representação. Todas as identidades estão localizadas no espaço e no tempo simbólico. Elas têm aquilo que Edward Said (1990) chama de suas "geografias imaginárias" ou suas "paisagens" características, seu senso de "lugar", de "casa/lar", bem como suas localizações no tempo, nas narrativas que conectam o indivíduo a eventos históricos mais importantes.

Alguns teóricos argumentam que o efeito geral desses processos globais tem sido o de enfraquecer formas nacionais de identidade cultural. Ocorre com essa prática, uma espécie de tentativa de desmantelamento da identidade nacional. As identidades nacionais permanecem, embora a tentativa de solapamento, mas as identidades locais, regionais e comunitárias têm se tornado mais importante. Constata-se, pois, uma quebra de paradigmas no sentido de uma 


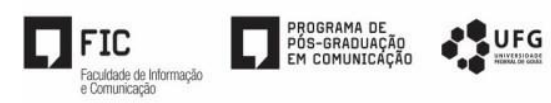

metamorfose entre um estado anterior e um novo estágio, o do desejo, não considerando o novo como uma ruptura radical, e sim tributária, por que não dizer, das várias transformações culturais que já atravessamos ao longo de nossa existência. Poderíamos chamar este momento de um intervalo entre a modernidade e a pós-modernidade. Pesquisadores ressaltam haver uma mudança que está, ainda, se processando, que é, justamente, essa passagem da modernidade para a pós-modernidade. Mas não só a sociedade e os paradigmas mudaram. Haverá uma mudança, também, na forma de analisar o processo de construção social, deixando de lado aquela forma de análise que se detinha em verificar macroestruturas históricas. A fenomenologia e o pragmatismo, por exemplo, serão importantes na consolidação das microteorias. Abandonam-se as grandes narrativas, de acordo com Lyotard (1989), e passa-se a orientar-se por novos paradigmas que rompem com a velha ordem.

O momento de passagem é uma característica recorrente na história. Simmel, na virada do século XIX para o XX, percebeu uma transformação cultural na Alemanha e procurou, justamente, compreender esse conflito. Para ele, é natural a mudança nas formas culturais: “[...] esse processo se apresenta de maneira visível e designável como a supressão da forma antiga por uma nova” (SIMMEL, 2013, p. 120). Esse aspecto observado pelo sociólogo alemão, que se debruçou em exemplos como o dinheiro, entre outras situações do cotidiano, é apenas uma ilustração da recorrência de mudanças de paradigma tanto quanto a que se observa hoje em direção a uma sensibilidade pós-moderna. Nesse tipo de sensibilidade, existe algo que nos orienta para o sentimento trágico da existência.

Não é o caso de nos aprofundarmos sobre isso agora. Porém, para melhor explicitarmos o quadro na entrada desta segunda quinzena do milênio, quadro esse que tem relação direta com nosso tema, é imperioso ressaltar, com Simmel, talvez influenciado por seu contemporâneo Max Weber, autor da célebre expressão de "desencantamento do mundo", que “[...] a multiplicidade e a complicação crescentes da vida não eliminam a sequência dos três termos - desejo, meio e fim" (2011, p. 13). Mais adiante, Simmel afirma: “A consciência se detém nos meios. Os fins últimos, que conferem sentido a toda a cadeia, desaparecem do horizonte visível” (2011, p. 14). Podemos interpretar esse "desaparecer do horizonte visível" como certo lamento de Simmel. E isso fica tão mais evidente quando ele caracteriza o dinheiro como aquilo que nos remete à impessoalidade, ou seja, ao caráter impessoal do dinheiro (SIMMEL, 2013, p. 21). 
Quando Simmel analisa Schopenhauer e Nietzsche (2011), o sociólogo alemão aborda questões diretamente relacionadas ao tema da pós-modernidade, no sentido de que o racionalismo não explica a concepção geral do homem, da mesma forma que Lash reflete sobre o desejo, ou seja, a lógica não é mais o fundamento último desse homem, a razão e o conhecimento não mais o centro da vida e que a razão não estabelece os fins, e sim a vontade (tema preferencial de Schopenhauer). Simmel, na obra intitulada "Schopenhauer \& Nietzsche" (2011), irá concluir, pois que, afinal de contas, nos faltaria um fim último para a vida e que essa incompletude, paradoxalmente, nos estimula na busca dessa finalidade ontológica. E assim foi com o Cristianismo, no entender de Simmel, mas que, ao longo do tempo, esse caminho perdeu o encanto. Mas não o anseio pelo fim. "Essa luta contra nós mesmos [o homem] produziu um ideal negativo, anulando o Eu empírico. Nietzsche foi o primeiro a tentar a superação por meio de uma elevação dos elementos positivos da vida" (SIMMEL, 2011, p. 190). De certa maneira, esse é o espírito da tragédia em Simmel que nos aproxima da sensibilidade pós-moderna via Nietzsche e Lash: intensificar a vida.

\subsection{MAFFESOLI E LASH: SER PÓS-MODERNO}

Seria apressado falar em crise da Sociologia com o advento, para muitos autores, da pós-modernidade? Esta é, em termos sucintos, a hipótese de Lash. Um dos sociólogos contemporâneos tem se sobressaído nesse debate e causado até certa polêmica por sua defesa do "homem pós-moderno". Trata-se de Maffesoli, aqui considerado como o fundador de uma "estética sociológica" do imaginário cotidiano. Maffesoli recebe muitas críticas, no entanto, tanto direta quanto indiretamente. Lipovetsky (2004), por exemplo, afirma que a pósmodernidade já passou, enquanto Bruno Latour (1994) garante: jamais fomos modernos. Porém, não seria, do nosso ponto de vista, associar a ideia de pós-modernidade neotribal em Maffesoli com a questão do desejo em Lash. Isso porque são paradoxos em evidências nos tempos atuais.

Mas Maffesoli insiste na complexidade pós-moderna e lidera uma corrente de seguidores que se multiplicam, principalmente entre alunos e pesquisadores do CEAq, o Centro de Estudos sobre o Atual e o Cotidiano, na Sorbonne, e instituições de ensino superior no Brasil, que utilizam o imaginário como viés fenomenológico para uma análise empírica das sociabilidades contemporâneas (que, no vocabulário maffesoliano, poderíamos traduzir por "socialidades pós-modernas"). Nisso reside a sua proposta de "reencantamento do 
mundo", criticada, em muitos casos, por excesso de generalização, inclusive por seu amigo Edgar Morin (2004), e que, para Maffesoli, merece a designação de pós-moderna. E, da forma como analisamos, de desejo, conforme Lash.

Maffesoli procura na dialética a resposta para os fenômenos sociais. O reencantamento, portanto, passa pelo imaginário, o equilíbrio entre pulsões e intimações do meio social. Aqui temos uma possível relação com a tese de Lash ao resgatar Deleuze e Nietzsche. Imaginário, para Maffesoli, é a realidade. A realidade de um cotidiano que deve merecer, segundo ele, uma investigação mais atenta e menos preconceituosa por parte da ciência. Maffesoli absorveu a ideia durandiana de "trajeto antropológico" (em Maffesoli, equivale à "centralidade subterrânea"), que é quando se constrói uma bacia semântica (metáfora também de autoria do antropólogo Gilbert Durand) inundada por uma força emocional também racionalizadora. Longe de ser datada, a questão "pós" ainda é motivo de grande polêmica no meio acadêmico e sociológico, especialmente.

A sociedade não se reconhece mais só na modernidade, que preconizava um futuro seguro e uma trajetória de vida linear (poderíamos dizer, também, verticalizada). Hoje, parece consenso que as novas sociabilidades desestabilizaram o paradigma do progresso histórico, da segurança profissional e da proteção do Estado. De um lado, há os que defendem o "pós", como Maffesoli (2004). De outro, há os que são contra, como Lipovetsky (2004), segundo o qual a pós-modernidade teve uma existência curta e o que prevalece agora é o prefixo "hiper": “[...] o rótulo pós-moderno já ganhou rugas, tendo esgotado sua capacidade de anunciar o mundo que se anuncia" (2004, p.52). Outros, porém, procuram uma leitura menos apaixonada desse fenômeno, porém não menos crítica. Lash, mesmo não erguendo bandeiras, oferece, com seu trabalho sobre o desejo, noções convergentes com as de Maffesoli.

Maffesoli se vale da denominada Sociologia Compreensiva, oriunda do sociólogo alemão Max Weber (1864-1920). Trata-se de buscar na pluralidade de "fatos" a base epistemológica de seu estudo da sociedade pós-moderna. $\mathrm{O}$ fato de privilegiar a visão (dos fatos sociais) antes plural do que monocórdica faz desse método de investigação uma proposta aparentemente anárquica (sem ordem). Porém, é desse mesmo anarquismo, desde que visto sob o ângulo de uma metodologia, que ela se forma e se fundamenta, buscando-se não hierarquizar os temas sociológicos. É no comportamento, muitas vezes considerado histérico, que a sociedade se vê. É a "parte do diabo" (Maffesoli). É aceitar o trágico que se instala; aquele trágico que pode ser mostrado, e não demonstrado. Segundo Maffesoli, a 
modernidade se preocupava em querer concluir qualquer ideia, tese ou argumento, o que, na opinião dele, sufocava um pensamento plural. “[...] o mundo, sua retórica, seus feitos são, essencialmente, plurais, não se prestam a uma conclusão, mas sim a uma abertura [...]. Não devem, portanto, constituir objeto de uma demonstração, mas sim de uma mostração" (1998, p. 114). Lipovetsky, porém, não entende a questão "pós" da mesma forma. Para ele, a expressão pós é ambígua e desajeitada, "para não dizer vaga” (2004, p. 52).

\section{REDES SOCIAIS, UM IMPERATIVO ATMOSFÉRICO}

Pergunta-se: presenciamos uma mudança de paradigma para uma sensibilidade pósmoderna, conforme Maffesoli? Esta é a questão que colocamos: como tratar de uma sociedade que, segundo Maffesoli, não mais aceita, passivamente, o ordenamento como regra e o progresso como solução? Vive-se, apesar da política, a efemeridade do cotidiano. Não estamos na sociedade da informação, e sim na sociedade do contato. Ou desejo, segundo Lash. É isso o que mais funciona. É melhor o caos do que o excesso de organização. A política, que procura regular a sociedade, agora é vista como um mal necessário. Maffesoli ainda fala do dionisíaco que aflora de uma atitude não-racional, com seu próprio código. $\mathrm{O}$ que Maffesoli acentua para justificar sua tese é a importância que os atores sociais dão para o cotidiano, o presente, o aqui-e-agora. O futuro é passado. Conta a forma de viver, o "presenteísmo". Pode-se abdicar de uma tarefa para curtir o ócio. O espetáculo é uma forma de êxtase. Todos esperam pela hora do show.

O particular passou a ser visto como um atributo coletivo. É isso o que Maffesoli chama de "socialidade", algo que se constrói na relação com o Outro. O "eu" se fortalece no mascaramento. Ora assumo um determinado papel, ora outro. E todos esses papéis são válidos. Um não é melhor do que o outro. Maffesoli pode ser considerado autor de uma sociologia do cotidiano. Há quem identifique nele um híbrido de sociólogo, antropólogo e filósofo. Sociólogo por causa de sua formação específica nessa área e por sua admiração pelo trabalho de Weber, Émile Durkheim e Georg Simmel. Antropólogo - de caráter urbano - por sua filiação fenomenológica aos estudos de Gilbert Durand. E filósofo por sua admiração de Nietzsche, que, admitiu, lhe serve como um "par de óculos".

Todos estes autores inspiram Maffesoli a falar de uma saturação do mundo moderno centrada no substancialismo, isto é, o de que algo seja algo ou signifique aquele atributo ao 


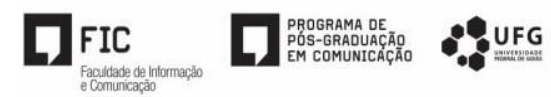

qual se refere. Para Maffesoli, um mito deixa de existir ou deixa de ser. A Sociologia Compreensiva em Maffesoli é um imperativo atmosférico, o da animalidade humana, e este fenômeno passa a adquirir importância, neste século, porque a sociedade contemporânea já não se reconhece na lógica cartesiana dos três séculos anteriores, lógica essa regida pelo ideal de um futuro seguro através da força de trabalho. Um abismo se abre. Mas (e aí entra um dos aspectos interessantes de uma leitura sociológica de cunho compreensivo) uma das maneiras de conviver com essa "perda" é se distanciando, sempre e cada vez mais, da única certeza que temos na vida, a morte. Passamos, então, a dar mais importância ao cotidiano, ao vivido, ao presente, à festa, ao prazer. Mesmo que tudo isso - e por isso mesmo - seja efêmero. A obra de Maffesoli, em suma, destaca que uma ambiência emocional (ou seja, as trocas e possibilidades de contato) toma lugar da argumentação. Melhor ouvir do que explicar. O projeto de vida são identificações e não identidades. O desejo, em Lash, aproxima-se dessa tese.

Não seria exagero dizer, por tudo isso salientado antes, que Maffesoli é o teórico que se impõe como referência quando se fala de uma fenomenologia do imaginário baseada no cotidiano. Maffesoli insiste em dar importância para o imaterial, a aura e o não-racional nas relações sociais. Outra questão interessante na obra dele é que o Ocidente não teria se rendido apenas ao trabalho árduo para ter, como recompensa, um futuro melhor. Não. Maffesoli acredita em um estar-junto societal. Ou seja, a vida que se cristaliza no instante: um instante mágico, afirmativo. Este instante é a marca da pós-modernidade. Na modernidade, porém, o mito prometeico (trabalhar para colher os frutos) assumia um papel de destaque, o de um sujeito institucionalizado e racional. A modernidade era fundada no individualismo: se eu trabalhar direito serei recompensado. Na direção oposta, o mito dionisíaco da pósmodernidade valoriza a exacerbação dos afetos, o orgiástico e o tribalismo. Grupos se juntam com objetivos comuns. A tribo é fechada, mas solidária.

Reconhecer estas singularidades do cotidiano - considerado espaço-matriz - está na base do "formismo" maffesoliano. "Formismo" é a rejeição do dualismo, da lógica da separação, do "ou” isto “ou” aquilo. Maffesoli faz um jogo de palavras, e assinala que a forma é formante, e não formal. Com isso, o autor procura uma categoria estruturante para dar conta da polissemia do cotidiano. Esta reversibilidade é característica do pensamento maffesoliano: a beleza do feio, o fundo das aparências, a razão sensível. E isso tudo está interligado. Tratase de um recurso metodológico que procura valorizar as "formas" de socialidade, nem que o 
pesquisador se afaste dos julgamentos. "O jogo das formas permite medir a eficácia do anódino", afirma Maffesoli (2007, p. 34). É a partir dessa ideia "formista" que Maffesoli encontra um terreno fértil para se lançar ao estudo de uma sociedade vitalista e orgiástica.

\section{COMUNICAÇÃO PARA UMA CONDIÇÃO PÓS-MODERNA}

Para falarmos da sociedade contemporânea, não podemos negligenciar um primeiro questionamento: o que define o saber? Maffesoli, de forma latente, faz a si mesmo esse mesmo tipo de pergunta e, para tentar respondê-la, retrocede no tempo para projetar o futuro: utiliza-se de pensadores que também questionam o "ocidentalismo" (este saber do jeito que pensamos que seja) e, por outro lado, valorizam o cotidiano (como Simmel). Esta visão crítica do mito prometeico e a consciência da morte configuram o embrião da ideia de pósmodernidade na linha do imaginário. Um filósofo francês, Lyotard, alavancou a discussão sobre a pós-modernidade por tratar desse assunto como sendo o de uma natureza epistemológica. Autor de "A condição pós-moderna”, Lyotard observa diversas maneiras de se ver o social. A partir desse pressuposto, ele abre a discussão para situações que desestruturam a dialética tese-antítese-síntese. Os metarrelatos já não significam muita coisa. Há, na pós-modernidade, uma desconfiança em relação aos instrumentos do saber. Aliás, como afirmar que um saber é verdadeiro?

Em “A condição pós-moderna", Lyotard opina que o saber pós-moderno "refina nossa sensibilidade para as diferenças e reforça nossa capacidade de suportar o incomensurável" (1989, p.13). Com isso, os valores modernos começam a ser questionados, inclusive no que diz respeito à obra de arte. Não há como não estabelecer uma cesura entre estes dois tipos de manifestações, a que diz respeito ao utilitarismo, típico da modernidade, e a que diz respeito ao dispêndio, típico da pós-modernidade. $\mathrm{O}$ aspecto que Lyotard aborda é o de que o saber científico não é todo o saber. Assim, a obra de arte culta não seria toda a obra de arte. $\mathrm{O}$ importante, aqui, é o fato de que se estabelece uma crise entre o conhecimento dito científico e o que Lyotard chama de narrativo, apesar de, segundo ele, não haver pensamento por oposições em relação ao saber pós-moderno.

Lyotard afirma que "enquanto o saber narrativo toma o científico como uma variedade entre as culturas narrativas, o saber científico interroga-se sobre a validade dos enunciados narrativos" (1989, p.61), adotando um raciocínio por oposição incongruente com a natureza 
da pós-modernidade. Lyotard não é um pensador pós-moderno, e sim um pensador da pósmodernidade, a exemplo do italiano Gianni Vattimo. Talvez percebamos neles um vício de origem, o da filosofia como instrumento de esclarecimento. O que Maffesoli propõe, ao contrário, é uma reflexão que não tem o intuito de desmascarar o que parece, para outros pensadores, encoberto.

Abrimos parênteses para outro autor. Trata-se de Paul Feyerabend, que escreveu "Contra o método" para mostrar como diversas descobertas científicas podem ter sido fruto do acaso. Esta tese abala o discurso científico, que não aceita o pressuposto do acaso para o exercício da racionalidade. Tudo deve ser (com)provado. Mas como comprovar o estágio em que a sociedade se encontra? Ou melhor: como um sociólogo pode falar de algo nãocomprovável estatisticamente? "Fatos, operações e resultados que constituem as ciências não têm uma estrutura comum" (FEYERABEND, 1993, p. 7). Com isso, o filósofo austríaco critica o saber tradicional, aquele assentado no reducionismo. Ao lado de Karl Popper e de Thomas Kuhn, Paul Feyerabend é considerado um dos principais renovadores da história das ciências no século XX. Atacou duramente a pretensão de neutralidade das pesquisas científicas.

Maffesoli também faz o mesmo. O autor de "Adeus à razão" (1987) criou o princípio do tudo vale: retirar elementos para análise ou construção dos lugares de onde bem se entender e que pareçam mais adequados para a exposição daquela ideia. Mesmo admitindo-se que se trata de um anarquismo epistemológico, este procedimento de Feyerabend não é de todo improcedente. As descobertas ditas científicas não são puramente racionais, oriundas apenas da razão. E a imaginação não tem nada de científico. Este tipo de estudo, o de uma pluralidade de saberes, dialoga com as percepções de Bachelard e, contemporaneamente, com a Sociologia Compreensiva em Maffesoli. "Foi a reflexão sobre a experiência do cogito que deu a Descartes seu critério de clareza e de distinção", afirma Bachelard (2008, p. 78). A palavra "reflexão", na frase de Bachelard, pode ser substituída, sem prejuízo de seu entendimento, por "imaginação": refletir é imaginar (mesmo quando a reflexão é escópica; ou seja, mesmo diante de um espelho, refletimos a e sobre a matéria que nos distingue).

Pois a Sociologia Compreensiva maffesoliana ${ }^{3}$ procura o conhecimento como obra da imaginação. Compreender, etimologicamente falando, ensina Maffesoli, é “nascer com”, e se

\footnotetext{
${ }^{3}$ Maffesoli se inspirou em Max Weber, cuja proposta "compreensiva" se apoia na convicção segundo a qual as pessoas não são apenas agentes portadores de estruturas, mas sim produtores ativos, depositários de um
}

Comun. \& Inf., Goiânia, GO, v. 21, n. 2, p. 32-50, jun./set. 2018. 
somos uma individualidade que "nasce com", também somos o coletivo social, algo originário do complexo (e "complexo" é um tecido, e, por ser tecido, é, de novo, tecido "com") organismo humano e social. Nossa sociedade ocidental contemporânea atravessa um momento ímpar, e é dessa singularidade que Maffesoli nos fala. Logo, não podemos utilizar a medida cartesiana para dar conta de uma pesquisa que clama por ser, acima de tudo, polissêmica, e cujos sentidos não se enquadrariam neste ou naquele conceito (o conceito da certeza). Sabemos, com Edgar Morin, que o cientificismo é uma doutrina que reconhece como única verdade a do método científico. Mas qual é o método científico da Sociologia Compreensiva?

\section{O PROJETO DA MODERNIDADE}

Derivada de Max Weber, a expressão procura, em Maffesoli, a confluência de fatores que originam a sociedade. Estes fatores, como apontamos antes, são plurais. Pluralidade que nos remete à complexidade dos atores sociais que extrapolam uma visão monocromática de indivíduos considerados idênticos, mas que, na verdade, se estão juntos em torno de uma mesma raiz antropológica, a de viver na sociedade estruturada a partir dos elementos constitutivos do seu ser, diferem-se, por outro lado, uns dos outros. É o uno e o todo que formam a base social. Porém, para a doutrina cientificista, a verdade da existência é uma só, a que se afasta de um relativismo: pôr em relação. Maffesoli, contrário ao estatuto acadêmico tradicional, reitera a necessidade de relativizarmos. Relativizar é o tema pós-modernidade, porque existe um jogo em questão, que é o de valorizar um modo de ser sensível à complexidade do instante, e, mais significativo de tudo, integrar as contradições próprias de um sentimento antes trágico do que dramático da existência, como assinalamos anteriormente.

Conforme Carlos A. Gadea, reforçando a tese de Maffesoli, a modernidade se apresenta como, em primeiro lugar, um projeto, o que, por si só, se afastaria da lógica pósmoderna. E mais: um projeto de emancipação social, que prevê uma expansão rumo ao progresso através do "culto à razão". Assim, o projeto da modernidade, ainda segundo Gadea, teria por objetivo o domínio do homem sobre a natureza - contrário à visão holística e ecológica da pós-modernidade - e o domínio sobre as relações sociais. "Esta visão afirmativa da modernidade é a que sustentam os ideólogos do Iluminismo, para os quais a modernidade é

conhecimento importante. A meta é uma explicação compreensiva do social. O que importa é a história de vida da fonte, e não a história congelada no tempo, nostálgica, passada. O passado, o presente e o futuro misturam-se.

Comun. \& Inf., Goiânia, GO, v. 21, n. 2, p. 32-50, jun./set. 2018. 
a chegada do homem a sua maioridade, o reinado da ditosa Razão" (GADEA, 2001, p. 117). E Maffesoli é o teórico que assume a condição pós-moderna, enquanto outros preferem um olhar mais cauteloso e distante do cotidiano.

Já no discurso pós-moderno, compara Gadea, e uma comparação é inevitável, a crença no "sujeito universal" sofre um abalo, junto com a ideia de consenso e regulação do mundo. A linguagem, dessa forma, também muda, para aceitar uma possível ambiguidade nos laços sociais da pós-modernidade. O que é a verdade? A essência, hoje em dia, tem alguma importância? O modelo de sociedade (e das grandes narrativas como o socialismo), em tempos pós-modernos, ainda faz sentido? Não estaríamos nos afastando de um modelo que deu mostras de saturação? Se assim fosse, como e de que forma preencher esse vazio? Esta mudança de mentalidade nos remete à observação de Maffesoli sobre o que se pensava na modernidade e o que se pensa hoje. A crítica da modernidade em Maffesoli aponta para o monoteísmo (a redução da polissemia do real a um único valor), o longínquo (a verdadeira vida está em outro lugar) e à separação das coisas (a natureza é uma coisa diferente da cultura). Daí surge a Sociologia Compreensiva, como negação disso.

\section{CONSIDERAÇÕES FINAIS}

Na perspectiva compreensiva, como se viu antes, verdade é pôr em relação. É um novo laço social de que fala Maffesoli. A noção de novo, porém, não é a mesma da modernidade, e sim a de "outro", que não exclui, necessariamente, o instituído. Este novo laço social é uma concepção trágica da existência, que, para Nietzsche, seria o niilismo, a ausência de fundamento na vida e a verdade morta. Como trágico entende-se: gozar o melhor possível do que se pode gozar; acomodar-se às contradições; não agir desnecessariamente sobre algo a respeito do qual não se pode mesmo nada; usufruir o aqui-e-agora (carpe diem); tolerar o outro, sobretudo quando suas práticas sociais não correspondem ao seu estilo de vida; esperar para ver; aceitar o destino. Ao contrário, uma concepção dramática da existência valoriza antes a necessidade de superação dialética das contradições; a crença no ideal democrático e na moral imposta de cima, instituída (como se disse); o princípio explicativo da sociedade pela via econômica; a funcionalidade dos serviços e a identidade única.

Maffesoli se afasta dos julgamentos, mas escreveu um livro queixoso: “A república dos bons sentimentos" (2009). É um Maffesoli diferente nesse trabalho: deixa de lado suas 


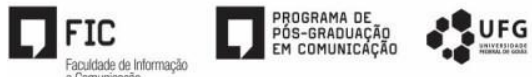

teorias (a do tribalismo, a do nomadismo e a da transfiguração política) e parte para o ataque contra políticos e jornalistas. Maffesoli defende o poeta e o pensador, que não se acomodam ao discurso oficial. Defende um cultivo intelectual que só cresce na humildade, mas forte, enraizado no cotidiano. Este é um sociólogo diferente, e por ser diferente é que se justificaria um trabalho pontual em relação as suas ideias, a sua forma de pensar, às raízes de sua história acadêmica, ao seu estilo, ao seu propósito sociológico. Trata-se de um método ensaístico de investigação que permite um olhar anarquista da emergente sociedade pós-moderna. $\mathrm{O}$ fato de pensarmos o relativismo como uma forma inclusivista de pesquisa, sem menosprezar também a objetividade, não traria um resultado mais fiel e próximo do significado de uma Sociologia Comprensiva? A Sociologia Compreensiva, por meio do relativismo, não ampliaria o conteúdo da pesquisa acadêmica, situando-a na lógica da pluralidade do conhecimento e inserindo conteúdo proveniente até da intuição do pesquisador? Não seria a Sociologia Compreensiva, enfim, uma maneira de dar conta, academicamente falando, das novas tendências e sensibilidades da pesquisa científica contemporânea?

Maffesoli propõe um novo estado da pesquisa e, com isso, renova a matriz teórica. Em relação ao pensamento crítico, Maffesoli oferece abordagens transversais. É o caso da inclusão na sua obra do positivismo de Auguste Comte, que o inspirou a refletir sobre um “poder espiritual" e um "acordo dos espíritos". É no caráter proteiforme (que assume diferentes formas) do positivismo, e não só o de um regramento social, que Maffesoli investe e pode surpreender tanto seus críticos quanto seus admiradores. A crítica, não apenas como visão desalienadora da sociedade, mas também ao atacar certos profissionais, principalmente jornalistas, analistas sociais e políticos, é recorrente nos seus livros. Incluir, em Maffesoli, tem um caráter transdisciplinar e anárquico, epistemologicamente falando, semelhante à tese do "tudo vale" em Feyerabend.

Se caso algum determinado pensamento ou autor "serve", inclui-se. A rejeição, para Maffesoli, é descartada por ter como base a lógica do "dever-ser", que o autor tanto combate. Estas três categorias, portanto, estão presentes em Maffesoli e moldam um estilo que poderíamos denominar de paratático. Ou seja, com o conteúdo é mais sugerido do que explicitado, é mais ensaístico do que exato, existem brechas que passam a ser preenchidas pelo leitor. Weber admite que "a sociologia tenta abranger também vários fenômenos irracionais, isto é, míticos, proféticos, espirituais, bem como afetivos" (2002, p. 32). Podemos observar que Maffesoli faz uma leitura orgânica de Weber, no sentido de profunda, e não 
superficial, dele, Weber, e de outros autores que costumam ser taxados por apenas um aspecto de sua obra. O exemplo mais notório é o de Comte, conhecido como o pai do "positivismo", sem que se relativize o que de satisfatório se possa tirar ou abstrair desse "conceito". Pelo viés da Sociologia Compreensiva, concluindo, é possível incluirmos na análise uma forma de raciocínio similar àquilo que estamos descrevendo, e julgamos ser isso extremamente necessário para que o investigador e o "objeto" de sua investigação falem a mesma língua, assim como Lash sobre o desejo, Hall sobre o sujeito sociológico e, finalmente, Maffesoli sobre o imaginário cotidiano e neotribal.

\section{REFERÊNCIAS}

BACHELARD, G. Estudos. Rio de Janeiro: Contraponto, 2008.

BARTHES, R. O prazer do texto. São Paulo: Perspectiva, 1987.

DURAND, G. As estruturas antropológicas do imaginário. São Paulo: Martins Fontes, 1997.

DURAND, G. O imaginário. Ensaio acerca das ciências e da filosofia da imagem. Rio de Janeiro: Difel, 1998.

FEYERABEND, P. Adeus à razão. Lisboa: Edições 70, 1991.

FEYERABEND, P. Contra o método. Lisboa: Relógio d’Água, 1993.

FOUCAULT, M. O que é um autor? Lisboa: Passagens, 1992.

GOHN, M G. Teorias dos movimentos sociais. Paradigmas clássicos e contemporâneos. São Paulo: Edições Loyola, 1997.

HALL, S. A identidade cultural na pós-modernidade. Rio de Janeiro. Lamparina, 2014.

LASH, S. Sociología del posmodernismo. Amorrortu: Buenos Aires, 1997.

LATOUR, B. Jamais fomos modernos. Rio de Janeiro: Editora 34, 2009.

LIPOVETSKY, G. Os tempos hipermodernos. São Paulo: Barcarolla, 2004.

LYOTARD, J.F. A condição pós-moderna. Lisboa: Gradiva, 1989.

MAFFESOLI, M. O conhecimento comum. Porto Alegre: Sulina, 2007. 
MAFFESOLI, M. O tempo das tribos. O declínio do individualismo nas sociedades de massa. Rio de Janeiro: Forense Universitária, 2000.

MAFFESOLI, M. Elogio da razão sensível. Petrópolis: Vozes, 1998.

MAFFESOLI, M. O instante eterno. Lisboa: Instituto Piaget, 2001.

MAFFESOLI, M. A república dos bons sentimentos. São Paulo: Iluminuras, 2009.

MAFFESOLI, M. A parte do diabo. Resumo da subversão pós-moderna. Rio de Janeiro: Record, 2004.

MAFFESOLI, M. Quem é... Michel Maffesoli. Entrevistas com Christophe Bourseiller. DP et Alii. Petrópolis, RJ, 2011.

MORIN, E. Introdução ao pensamento complexo. Lisboa: Instituto Piaget, 1991.

MORIN, E. O método 6: Ética. Porto Alegre: Sulina, 2005.

NIETZSCHE, F. O nascimento da tragédia. Ou helenismo e pessimismo. São Paulo: Companhia das Letras, 2007.

NIETZSCHE, F. A origem da tragédia. Lisboa: Guimarães Editores, 2002.

SAID, E. W. Orientalismo. O Oriente como invenção do Ocidente. São Paulo: Companhia das Letras, 1990.

SIMMEL, G. Schopenhauer \& Nietzsche. Rio de Janeiro: Contraponto, 2011.

SIMMEL, G. O conflito da cultura moderna e outros escritos. São Paulo: SENAC, 2013.

VATTIMO, G. O fim da modernidade. Niilismo e hermenêutica na cultura pós-moderna. São Paulo: Martins Fontes, 2002.

VATTIMO, G. A sociedade transparente. Lisboa: Relógio D’Água, 1992.

WATIER, P. Uma introdução à Sociologia Compreensiva. Rio de Janeiro: Forense Universitária, 2009.

WEBER, M. Conceitos básicos de Sociologia. São Paulo: Centauro, 2002.

WUNENBURGER, J.J. A razão contraditória. Lisboa: Instituto Piaget, 1995.

WUNENBURGER, J.J. O imaginário. São Paulo, Edições Loyola, 2007. 